\title{
O BRINCAR NO HOSPITAL: UMA SELF DE ENFERMEIROS QUE ATUAM EM UNIDADE PEDIÁTRICA
}

\section{PLAYING IN HOSPITAL: A SELF OF NURSES ACTING IN A PEDIATRIC UNIT}

\section{JUGANDO EN EL HOSPITAL: UNA SELF DE ENFERMERAS TRABAJANDO EN UNA UNIDAD PEDIÁTRICA}

\author{
Arinete Veras Fontes Esteves ${ }^{1}$, Lílian Dornelles Santana de $\mathrm{Melo}^{2}$, Aderlaine da \\ Silva Sabino ${ }^{3}$, Marcos Vinícius Gusmão da Silva ${ }^{4}$, Joseir Saturnino Cristino ${ }^{5}$, Ellen Pessoa \\ Rocha $^{6}$
}

Como citar esse artigo: Esteves AVF, Melo LDS, Sabino AS, Silva MVG, Cristino JS, Rocha EP. O brincar no hospital: uma self de enfermeiros que atuam em unidade pediátrica. Rev Enferm Atenção Saúde [Internet]. 2021 [acesso em:__];10(1):e202104. Doi: https://doi.org/10.18554/reas.v10i1.3938

\begin{abstract}
RESUMO
Objetivo: Conhecer a importância da atividade do brincar sob a ótica do enfermeiro durante o cuidado à criança hospitalizada. Metodologia: Estudo descritivo-exploratório prospectivo, qualitativo. Realizou-se entrevista semiestruturada em unidade pediátrica de referência de um município no estado do Amazonas, no mês de janeiro de 2015. Participaram cinco enfermeiras que atuam na unidade pediátrica. Da análise, emergiram categorias temáticas: "A importância do brincar no olhar da Enfermagem como Direito da Criança." e "Obstáculos para inclusão da brincadeira no assistir à criança hospitalizada". Resultados: O brincar é relatado pelas enfermeiras como uma atividade ímpar durante a hospitalização. Entretanto, referem não inseri-lo por desconhecerem como realizá-lo, valorizando apenas procedimentos técnicos em suas ações de enfermagem, engessando o cuidado durante seu atendimento. Conclusão: $O$ brincar em clínica pediátrica deve ser uma atividade inserida no plano de cuidados dos enfermeiros.

Descritores: Percepção; Enfermagem; Jogos e Brinquedos; Criança Hospitalizada; Cuidado da Criança.
\end{abstract}

\footnotetext{
${ }^{1}$ Enfermeira. Doutora em ciências. Professora Associada da UFAM. Manaus-AM. Universidade Federal do Amazonas. arineteveras@ufam.edu.br

${ }^{2}$ Enfermeira. Residente em Enfermagem Obstétrica pela Secretaria de Saúde do Recife. Recife, PE, Brasil. Secretaria de Saúde do Recife-PE. enf.liliandornelles@gmail.com

${ }^{3}$ Enfermeira. Mestre em Enfermagem. Docente do Departamento de Enfermagem da Universidade Luterana de Manaus. Manaus, AM. aderlainesabino@yahoo.com.br

${ }^{4}$ Enfermeiro. Mestrando em Enfermagem pela Universidade Federal do Amazonas, associado à Universidade do Estado do Pará. Manaus, AM. Universidade Federal do Amazonas. vinicuruma@ hotmail.com

${ }^{5}$ Enfermeiro. Mestrando em Doenças Tropicais e Infecciosas pelo Programa de Pós-Graduação em Medicina Tropical (PPGMT) da Universidade do Estado do Amazonas (UEA) e Fundação de Medicina Tropical Dr. Heitor Vieira Dourado (FMT/HVD). Manaus-AM. Universidade Estadual do Amazonas. joseysaturnino@gmail.com

${ }^{6}$ Enfermeira. Mestre em Enfermagem. Enfermeira do Hospital Universitário Getúlio Vargas. Manaus, AM. Hospital Universitário Getúlio Vargas. rocha.ellen2011@hotmail.com
} 


\begin{abstract}
Objective: To know the importance of playing activity from the nurse's point of view during the care of hospitalized children. Methodology: Prospective, qualitative descriptive exploratory study. A semi-structured interview was carried out in a pediatric reference unit in a municipality in the state of Amazonas, in January 2015. Participants were five nurses who work in the unit. From the analysis, thematic categories emerged: "The importance of playing in the view of Nursing as the Right of the Child." And "Obstacles for the inclusion of playing in assisting hospitalized children". Results: Playing is reported by nurses as a unique activity during hospitalization. However, they refer not to insert it because they do not know how to do it, valuing only technical procedures in Nursing actions, plastering care during their assistance. Conclusion: Playing in a pediatric clinic should be an activity included in the nurses' care plan.
\end{abstract}

Descriptors: Nursing; Play and Playthings; Child, Hospitalized; Child Care; Pediatrics.

\title{
RESUMEN
}

Objetivo: Conocer la importancia de la actividad de juego desde el punto de vista de la enfermera durante el cuidado de niños hospitalizados. Metodología: Estudio exploratorio prospectivo, cualitativo, descriptivo. Se realizó una entrevista semiestructurada en una unidad de referencia pediátrica en un municipio del estado de Amazonas, en enero de 2015. Participaron cinco enfermeras que trabajan en la unidad. Del análisis, surgieron categorías temáticas: "La importancia de jugar desde la perspectiva de la Enfermería como el derecho del niño". Y "Obstáculos para la inclusión del juego en la asistencia a niños hospitalizados". Resultados: Las enfermeras informan que el juego es una actividad única durante la hospitalización, sin embargo, se refieren a no insertarlo porque no saben cómo hacerlo, valoran solo los procedimientos técnicos en las acciones de Enfermería, echan atención durante su cuidado. Conclusión: Jugar en una clínica pediátrica debería ser una actividad incluida en el plan de atención de enfermeira.

Descriptors: Enfermería; Juego e Implementos de Juego; Niño Hospitalizado; Cuidado del Niño; Pediatría.

\section{INTRODUÇÃO}

A brincadeira na educação infantil auxilia o desenvolvimento físico, social, afetivo e cognitivo do infante. A atividade lúdica é uma peça fundamental na estruturação do conhecimento da criança, pois o ato de brincar é algo espontâneo e motivador para a construção de relações interpessoais, promovendo um crescimento saudável e produtivo das crianças desde o nascimento à fase adulta, com noções de limites e laços afetivos de seu convívio social. $^{1}$

A criança tem a necessidade de brincar e esta ação não deve ser esquecida, principalmente quando adoecem e são hospitalizadas, pois a atividade lúdica desempenha papel importante para a promoção de um ambiente seguro. Neste sentindo, o brincar torna-se uma estratégia de adesão e adaptação ao tratamento, possibilitando a diminuição dos sentimentos de medo, ansiedade, 
irritabilidade e favorecendo a melhora do infante através do humor e da distração. ${ }^{2}$

Durante a doença, seguida de hospitalização, a criança interioriza o medo de separação dos pais, a ruptura da rotina e o temor quanto aos procedimentos invasivos que causam situações de desconforto em decorrência do tratamento, caracterizando-se como um momento

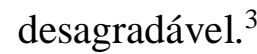

A utilização do brinquedo como ferramenta de cuidado do enfermeiro em unidade pediátrica é capaz de avaliar o emocional da criança, baseando-se na evidência da expressão dos sentimentos. Da mesma forma, estabelece vínculo com esta e sua família, promovendo a intervenção terapêutica adequada de acordo com a necessidade do infante. .-5 $^{4-5}$

Diante disto, a Resolução COFEN $\mathrm{N}^{\mathrm{o}} 546 / 2017$ vem ao encontro, reforçando que o enfermeiro que realiza assistência em unidade pediátrica deve desenvolver atividade de brincar com o brinquedo terapêutico durante a prestação de cuidados à criança em regime de internação, como ferramenta de intervenção na prescrição da Sistematização da Assistência de Enfermagem. ${ }^{6}$

Desta forma, entende-se que o brinquedo/brincar faz parte do cotidiano das crianças e seu uso deve ser estimulado, mesmo durante a internação, uma vez que a LEI $\mathrm{N}^{\circ} 11.104 / 2005$ estimula e auxilia essa prática, determinando que todas as unidades que atendam ao público infantil devam ter em suas instalações uma brinquedoteca para que a criança possa vivenciar seu mundo de faz de conta. ${ }^{7}$

O objetivo deste estudo foi conhecer a importância da atividade do brincar sob a ótica do enfermeiro durante o cuidado à criança hospitalizada.

\section{MÉTODO}

Estudo de abordagem qualitativa, de caráter descritivo-exploratório prospectivo, que buscou compreender a concepção do enfermeiro que trabalha em clínica cirúrgica pediátrica, sobre a atividade de brincar como dimensão do cuidado à criança hospitalizada.

O estudo foi desenvolvido no Instituto de Saúde da Criança do Amazonas (ICAM), uma unidade de atendimento à criança e ao adolescente da rede estadual de saúde de Manaus/Amazonas, composto por uma equipe multidisciplinar e multiprofissional.

O cenário da pesquisa foi a clínica cirúrgica do ICAM, que possui 22 leitos, distribuídos em quatro enfermarias. Participaram do estudo 5 enfermeiras que atuam na clínica cirúrgica, com participação de $80 \%$ das enfermeiras do 
horário diurno (quatro) e uma do plantão noturno, em virtude de recusa justificando excesso de trabalho. Como critério de inclusão, optou-se por entrevistar as enfermeiras que atuavam unicamente neste ambiente como concursadas da rede estadual de saúde há mais de 6 meses e que não estavam de férias. Teve como critério de exclusão: enfermeiras prestadoras de serviço de empresas terceirizadas, visto que há uma grande rotatividade dessas profissionais.

A coleta de dados ocorreu após aprovação do Comitê de Ética e Pesquisa da UFAM (CEP/UFAM) com CAAE $\mathrm{N}^{\circ}$ 31389814.9.0000.5020, seguindo as normas da Resolução 466/2012 do CNS. O anonimato foi mantido por pseudônimos, por meio de nomes de flores, impossibilitando a identificação dos sujeitos: Rosa, Jasmin, Flor de Laranjeira, Margarida e Tulipa.

A execução da coleta de dados ocorreu no período de dezembro de 2014 a janeiro de 2015. As enfermeiras foram abordadas na unidade; em primeiro momento foram explicados os objetivos da pesquisa com leitura do Termo de Consentimento Livre e Esclarecido e assinatura das participantes. Após a apresentação, realizou-se a aplicação do roteiro de entrevista semiestruturado, que foi gravado e, posteriormente, transcrito na íntegra. Cada entrevista durou em média 15 minutos, em decorrência de ter sido realizada durante a jornada de trabalho das enfermeiras que relatavam diversas atribuições que deveriam ser desenvolvidas naquele momento. ${ }^{8}$

A análise de dados foi embasada segundo as orientações e procedimentos de Minayo, 2014. Realizou-se leitura das transcrições e escuta atentiva dos áudios, a fim de evitar a perda de informações importantes, mantendo a fidedignidade das falas das colaboradoras da pesquisa. Utilizou-se Análise de Conteúdo com técnica de Análise Temática das falas, que aborda três etapas: pré-análise; exploração do material; tratamento dos resultados obtidos e interpretação para formação de categorias temáticas.

\section{RESULTADOS}

O conteúdo das falas explicitou 02 categorias temáticas, conforme a seguir: "A importância do brincar no olhar da enfermagem como direito da criança", e "Obstáculos para inclusão da brincadeira no assistir à criança hospitalizada". 


\section{A importância do brincar no olhar da enfermagem como direito da criança}

Identificou-se que as enfermeiras possuem conhecimento empírico sobre a importância do brinquedo e do brincar inserido no ambiente hospitalar, considerando esta atividade como um instrumento capaz de auxiliar no cuidado diário da criança hospitalizada.

É muito importante essa atividade dentro do hospital, porque diminui aquela tensão do procedimento invasivo e da experiência do pósoperatório. A criança, quando brinca, fica menos estressada e mais feliz[...] (Rosa, 10 anos de experiência).

Eu acredito que seja importante pelo fato da criança se distrair, [...] não ficar só no momento da doença (Jasmin, 3 anos de experiência).

$\mathrm{Na}$ percepção das profissionais entrevistadas, a importância da atividade de brincar no ambiente hospitalar está relacionada a momentos de descontração que diminuem a tensão e promovem bemestar na criança.

As enfermeiras percebem que o brinquedo pode ser utilizado como instrumento estimulante para o desenvolvimento físico, cognitivo e social. Entre seus benefícios também foi relatada a diminuição das tensões desencadeadas pela hospitalização, através da aproximação da rotina cotidiana que proporciona à criança momentos de divertimento.

[...] eu acho que tudo aquilo que a gente $v \hat{e}$, o desenvolvimento cognitivo, desenvolvimento motor, social, tudo isso eu acho que a criança que brinca, ela desenvolve muito mais rápido do que as outras (Flor de laranjeira, 14 anos de experiência).

A criança mantém com o brinquedo o vínculo que tem em casa normalmente. [...] a criança da cirúrgica não é uma criança doente, aquilo é só uma fase [...] então é importante que se mantenha as brincadeiras, [...] é um momento diferente ali pra eles, de rir e se divertir (Tulipa, 15 anos de experiência).

O brincar durante a hospitalização proporciona momentos de alegria e de interação da criança, contribuindo para uma rápida melhora do seu estado geral. $\mathrm{Na}$ perspectiva das enfermeiras, a criança hospitalizada em clínica cirúrgica não está doente, sendo este momento de internação apenas uma fase.

Você vê que depois que eles brincam ficam mais alegres, mais comunicativos, então assim, eu acho que brincar dá muito mais ânimo. [...] Você que acompanha a criança que está hospitalizada percebe nas poucas crianças que brincam aqui, uma melhora muito grande quando ela se diverte com qualquer coisa que faz (Flor de laranjeira, 14 anos de experiência). 
$\mathrm{Na}$ percepção das enfermeiras, quando a criança hospitalizada brinca ela vivencia momentos alegres, melhorando sua autoestima e ajudando na sua comunicação com as pessoas. Durante a prestação de cuidados, três enfermeiras relataram que executam momentos recreativos nas enfermarias, respeitando o direito de brincar que a criança possui.

Só eu que brinco com os pacientes, assim, mas não com brinquedo, a gente conversa, aí explica alguma coisa que vai fazer. Usando brinquedo, alguma coisa que estimule o cognitivo, eu não costumo usar (Flor de laranjeira, 14 anos de experiência).

Não faço nenhuma atividade de brincar. Tem muito procedimento pra fazer, aquelas coisas burocráticas também né, tudinho (Margarida, 28 anos de experiência).

As enfermeiras da clínica cirúrgica não disponibilizam de brinquedos para utilizarem durante a assistência. Entretanto, algumas aplicam estratégias recreativas como forma de distrair a criança antes da realização de procedimentos ou simplesmente para proporcionar um momento de descontração. Outras não realizam esta atividade justificando excesso de trabalho.

\section{[...] a gente não disponibiliza de} brinquedo aqui na unidade. Durante a visita eu brinco com a criança. [...] A brincadeira é só pra chamar a atenção, ou se tiver alguma coisa que a gente possa mexer ou pegar na mão da criança, brincar com ela de algum modo a gente brinca, mas não com brinquedo (Jasmin, 3 anos de experiência).

Nesse sentido, mesmo sem utilizar o brinquedo, a enfermeira proporciona um momento de distração para a criança durante as visitas com intuito de realizar uma brincadeira.

\section{Obstáculos para inclusão da brincadeira no assistir à criança hospitalizada}

Na percepção das enfermeiras, na clínica cirúrgica as atividades administrativas e assistenciais dificultam o desenvolvimento da atividade do brincar durante sua jornada de trabalho.

Sou só eu de enfermeira, né [...] a gente tem que dar conta, [...] às vezes a gente cobre duas clínicas e aí é difícil né (Margarida, 28 anos de serviço).

[...] no plantão é só um enfermeiro e é muito curativo e você tem que aprazar [...] (Flor de laranjeira, 14 anos de serviço).

As enfermeiras relatam, também, que tiveram uma formação deficiente quanto a essa prática específica, pois, as disciplinas eram voltadas para as doenças da infância, sem especificamente abordar a 
importância da utilização da atividade de brincar no ambiente hospitalar:

Tive pediatria, mas não focava nessa parte da assistência com brinquedo. [...] a gente não tem esse contato, a utilidade de um brinquedo ou porquê usar ele. [...] (Tulipa, 15 anos de experiência).

Teve saúde da criança, mas já faz tempo que eu me formei. Mudou a grade né?Abordaram muito sobre a área biopsicossocial, mas uma disciplina específica que abordasse sobre a importância da atividade de brincar não teve (Rosa, 10 anos de experiência).

\footnotetext{
Identifica-se que esse desconhecimento do tema brinquedo/brincar na formação acadêmica reflete na não utilização dessas ferramentas e na falta de preparo quanto à aplicação na assistência à criança hospitalizada.
}

Teve sim, porque assim, quando tu estás num estágio é uma coisa, quando tu chega na tua atividade profissional mesmo, é diferente, porque no estágio tu tem aquele horário, [...] tem aquela salinha de recreação [...].Quando profissional, a gente não tem esse horário não (Margarida, 28 anos de experiência).

Uma das enfermeiras mencionou que teve essa atividade de brincar durante o estágio; porém, não consegue relacionar a prática estudada na academia com o exercício da profissão devido à não disponibilidade de horário e ambiente físico inadequado.

\section{DISCUSSÃO}

$\mathrm{Na}$ percepção das enfermeiras, a brincadeira no ambiente de internação propicia à criança a transformação do momento vivido enquanto ser doente, minimizando seus medos, angústias e recusa ao tratamento, facilitando a interação com outras crianças, diante do ambiente acolhedor que oferece jogos, brinquedos, desenhos e leituras. Estes favorecem de forma positiva $o$ relacionamento com a equipe, bem como a aceitação dos procedimentos necessários no tratamento, reduzindo o tempo de internação. ${ }^{9}$

Vale ressaltar que o Estatuto da Criança e Adolescente, capítulo II, artigo 16, destaca o direito à liberdade, respeito e dignidade, afirmando que toda criança deve brincar e se divertir, ações estas que fazem parte de sua vida diária e desenvolvimento pessoal. ${ }^{10}$

Diante desta afirmativa, o brincar no ambiente hospitalar é a estratégia utilizada pelas crianças para o enfrentamento de situações estressantes, fato ancorado na Resolução N41/1995CONAND, que estabelece como um dos direitos do infante, no decorrer do processo 
de internação, que o enfermeiro deve realizar atividades recreativas, evitando as situações adversas que podem vir a influenciar no processo da recuperação de sua saúde. ${ }^{1,11}$

$\mathrm{Na}$ presença de algumas respostas obtidas, como o desconhecimento das legislações vigentes referentes ao exercício da profissão, destaca-se a necessidade de atualização e busca de qualificação para os enfermeiros que atuam na área da criança doente, quanto à Lei Federal $N^{\circ} 11.104 / 05$ e a Resolução COFEN 546/2017, que regem o exercício da profissão. ${ }^{6-7}$

Para a criança em idade escolar, os cuidados de enfermagem devem proporcionar estimulação, interesse e cooperação durante as práticas assistenciais com o brinquedo para melhorar o humor, aceitação, descontentamento e sofrimento emocional, principalmente em casos de internação prolongada, minimizando a ansiedade e o medo por meio da comunicação terapêutica. $^{12}$

Todavia, as enfermeiras reconhecem a importância da atividade de brincar inserida no ambiente hospitalar, apontando como benefícios a comunicação e socialização com os demais pacientes presentes na enfermaria, além da expressão de felicidade das crianças após a vivência de um momento recreativo, que transforma o hospital em um ambiente descontraído. ${ }^{13}$ Podemos perceber que o cuidar brincando é evidenciado nas falas das enfermeiras quando utilizam estratégias recreativas para proporcionar à criança um momento de descontração antes da execução de algum procedimento. Para a criança, o cuidar através de brincadeiras reduz a ansiedade e o medo dos procedimentos quando realizado com carinho e afeto. ${ }^{12}$

Nesta perspectiva, um estudo ${ }^{14}$ aponta que acompanhantes de crianças hospitalizadas identificam que o cuidar por meio do brincar deve ser uma atividade desenvolvida pelos profissionais da saúde, pois se sentem inseguros ao realizar brincadeiras com suas crianças, pelo fato de desconhecerem o modo correto de brincar neste momento de hospitalização. Diante disto, referem a necessidade de um profissional orientá-los na execução de brincadeiras em ambiente hospitalar.

Assim sendo, enfermeiras de unidades pediátricas consideram que $o$ brincar com o brinquedo é uma necessidade básica da criança, que deve ser inserido no plano terapêutico como instrumento de intervenção de enfermagem, com o objetivo de oferecer um cuidado baseado na relação de empatia, 
afeto e confiança, ampliando-a para além do cuidado à saúde física. ${ }^{15}$

A inserção da atividade de brincar nas práticas assistenciais de enfermagem no cuidado à criança hospitalizada é vista pelas enfermeiras, em estudo realizado, como ferramenta de lazer e terapia durante a internação infantil. Contudo, estas referem que são muitas as barreiras encontradas na rotina de trabalho e na própria condição clínica do infante que dificultam o uso desta atividade. ${ }^{16}$

Diante disso, entende-se que as enfermeiras compreendem a atividade de brincar como recurso terapêutico que facilita o processo de internação, possibilitando à criança uma maior sociabilização no ambiente hospitalar, autocuidado e fuga da realidade. Entretanto, a escassez de recursos lúdicos e estrutura inadequada contribuem para a não realização efetiva do brincar. ${ }^{13}$

Em relação à compreensão das enfermeiras sobre o uso do brinquedo e a existência de um espaço no hospital, âncora desse estudo, estas acreditam que a qualidade e aceitação do tratamento à criança doente melhoraria de forma significante. Porém, evidenciou-se que não houve nenhuma iniciativa durante a realização do estudo para o oferecimento de pratica lúdica no ambiente intrahospitalar.
A ausência da utilização do brinquedo como ferramenta no processo de cuidar da enfermagem pelas enfermeiras da pesquisa corrobora estudo $^{17}$, o qual identificou que aproximadamente quarenta e três por centos da equipe de Enfermagem nunca realizou atividade lúdica durante o cuidado à criança hospitalizada.

Entretanto, em outro estudo ${ }^{15} \mathrm{com}$ 20 enfermeiras de uma unidade pediátrica à respeito do uso do $\mathrm{BT}$, foi identificado que elas reconhecem seu benefício, mas não o utilizam com frequência, devido a pouca habilidade em manuseá-lo. Destas, $46,6 \%$ relatam que já o utilizaram como ferramenta instrucional no preparo de crianças para procedimentos; porém, de maneira esporádica e não sistematizada.

A deficiência do ensino do lúdico no componente curricular do curso de graduação é um fator importante para a não realização dessa prática na assistência de enfermagem na perspectiva das enfermeiras do estudo.

Ressalta-se que em um estudo ${ }^{18}$ sobre a metodologia da problematização do arco de Maguerez, a respeito do uso do brinquedo terapêutico com graduandos de enfermagem, identificou-se que a metodologia de ensino através do diálogo e da autonomia do aluno possibilita uma maior relação deste com a teoria e a prática, formando um enfermeiro 
capacitado no conhecimento coletivo e crítico para assistência.

\section{CONCLUSÃO}

O estudo possibilitou conhecer as percepções das enfermeiras e suas vivências em unidade pediátrica, no qual estas relataram não desenvolver atividade com o brinquedo durante o o cuidado junto às crianças hospitalizadas, mesmo reconhecendo sua importância. Destas, apenas uma profissional referiu brincar; porém, sem uso do brinquedo ou outra ferramenta, e, de forma empírica. Esta ausência foi também associada ao desconhecimento sobre a temática na academia durante a formação.

Diante deste panorama, observase a necessidade urgente do enfermeiro ter um olhar integral às necessidades da criança hospitalizada, buscando manter-se atualizado sobre o cuidar da criança. Este estudo identificou ainda a necessidade de atualização dos enfermeiros participantes da pesquisa sobre o assistir à criança durante sua hospitalização, inserindo o brinquedo terapêutico de forma sistemática e imprescindível no seu plano de cuidado, reconhecendo suas vantagens no processo do tratamento.

O olhar da enfermagem no cuidado à criança hospitalizada deve ser empático, observando o problema que esta vivencia e a clínica em que está internada, percebendo-a como um ser dotado de características peculiares, que necessita de uma assistência integral diferenciada, atendendo suas necessidades biopsicossociais, buscando sempre oferecer uma assistência de qualidade com o cuidado humanizado.

Em relação às limitações do estudo, pode-se mencionar o tamanho da amostra. Embora significativa quanto à população de enfermeiras da unidade e quanto ao tipo de análise, poderia ser ampliada em outros estudos para a equipe de técnicos de enfermagem que também atuam na assistência à criança hospitalizada.

\section{REFERÊNCIAS}

1. Santos CCS, Costa LF, Martins E. A prática educativa lúdica: uma ferramenta facilitadora na aprendizagem na educação infantil. Ensaios Pedagógicos [Internet]. 2015 [citado em 25 set 2017]. Disponível em: http://www.opet.com.br/faculdade/revist a-pedagogia/pdf/n10/ARTIGO6.pdf. 2. Abreu C, Correira F, Jácome P, Rodrigues S, Santos V. O direito de brincar também nos cuidados intensivos. Enformação [Internet]. jul-out 2017 [citado em 25 ago 2018]; 8:23-28. Disponível em: https://www.acenfermeiros.pt//files/uplo ad/revistas/enformacao-08-2017-w.pdf 3. Canêz JB, Gabatz RIB, Hense TD, Vaz VG, Marques RS, Milbrath VM. O brinquedo terapêutico no cuidado à criança hospitalizada. Rev Enfer Atual In 
Derme [Internet]. 2019 [citado em 24 jun 2020]; 88(26):1-9. Disponível em http://www.revistaenfermagematual.com .br/index.php/revista/article/view/129/43 7

4. Baldan JM, Santos CP, Matos APK, Wernet M. Adoção do brincar/brinquedo na prática assistencial à criança hospitalizada: trajetória de enfermeiros. Ciênc Cuid Saúde [Internet]. abr-jun 2014 [citado em 15 mar 2017]; 13(2):228-35. Disponível em: http://periodicos.uem.br/ojs/index.php/Ci encCuidSaude/article/view/15500/pdf_1 67

5. Silva SGT, Santos MA, Floriano CMF, Damião EBC, Campos FV, Rossato LM. Influence of therapeutic play on the anxiety of hospitalized school-age children: clinical trial. Rev Bras Enferm. [Internet]. 2017; 70(6):1244-9. doi: http://dx.doi.org/10.1590/0034-7167-20160353

6. Conselho Federal de Enfermagem (Brasil). Resolução no 546, de 09 de maio de 2017. Atualiza norma para utilização da técnica do brinquedo/brinquedo Terapêutico pela Equipe de Enfermagem na assistência à criança hospitalizada [Internet]. D.O.U., Brasília, DF, 17 maio 2019 [citado em 04 abr 2018]; Seção 1, (93):106.

Disponível em: http://www.in.gov.br/materia//asset_publisher/Kujrw0TZC2Mb/conten t/id/20219144/do1-2017-05-17resolucao-n-546-de-9-de-maio-de-201720219131

7. Presidência da República (Brasil). Lei $\mathrm{n}^{\circ} 11.104$, de 21 de março de 2005. Dispõe sobre a obrigatoriedade de instalação de brinquedotecas nas unidades de saúde que ofereçam atendimento pediátrico em regime de internação [Internet]. D.O.U., Brasília, DF, 22 mar 2005 [citado em 20 mar 2015]. Disponível em: http://www.planalto.gov.br/ccivil_03/_at o2004-2006/2005/lei/111104.htm
8. Minayo MCS. O desafio do conhecimento: pesquisa qualitativa em saúde. 14ed. São Paulo: Hucitec-

Abrasco; 2014.

9. Silva LD, Soares PP, Pereira CC,

Pereira ADA, Freitas HMB, Rangel, RF.

$\mathrm{O}$ brincar no enfrentamento do processo de hospitalização. Discip Sci, Ser Cienc Saúde [Internet]. 2018 [citado em 20 mar 2018]; 19(2):291-300. Disponível em: https://periodicos.ufn.edu.br/index.php/d isciplinarumS/article/view/2513.

10. Presidência da República (Brasil). Lei ${ }^{\circ}$ 8.069, de 13 de Julho de 1990. Dispõe sobre o Estatuto da Criança e do Adolescente e dá outras providências [Internet]. D.O.U., Brasília, DF, 27 set 1990 [citado em 06 jun 2015].

Disponível em:

http://www.planalto.gov.br/ccivil_03/leis /18069.htm

11. Conselho Nacional dos Direitos da Criança e do Adolescente (Brasil).

Resolução $n^{\circ} 41$, de 13 de outubro de 1995 [Internet], D.O.U., Brasília, DF, 17 out 1995 [citado em 20 mar 2015].

Disponível em:

https://www.mpdft.mp.br/portal/pdf/unid ades/promotorias/pdij/Legislacao $\% 20 \mathrm{e} \%$ 20Jurisprudencia/Res_41_95_Conanda.p df

12. Santos PM, Silva LF, Depianti JRB, Cursino EG, Ribeiro CA. Nursing care through the perception of hospitalized children. Rev Bras Enferm [Internet]. 2016 [citado em 20 jun 2018]; 69(4):646-53. Disponível em: http://www.scielo.br/pdf/reben/v69n4/00 34-7167-reben-69-04-0646.pdf

13. Fernandes MNF, Chaves FL, Nunes

JT, Costa ACPJ. O Brincar na percepção de enfermeiros em um Hospital Pediátrico do Maranhão. J Health Sci. [Internet]. 2017 [citado em 20 jun 2018]; 19(2):120-5. Disponível em: https://revista.pgsskroton.com/index.php /JHealthSci/article/view/3553

14. Sabino AS, Esteves AVF, Oliveira APP, Silva MVG. O conhecimento dos pais quanto ao processo do cuidar por 
meio do brincar. Cogitare Enferm.

[Internet]. 2018 [citado em 25 out 2018]; 23(2):e52849. Disponível em:

https://revistas.ufpr.br/cogitare/article/vi ew/52849/pdf

15. Oliveira CS, Maia EBS, Borba RIH, Ribeiro CA. Brinquedo terapêutico na assistência à criança: percepção de enfermeiros das unidades pediátricas de um hospital universitário. Rev Soc Bras Enferm Ped. [Internet]. 2015 [citado em 20 jun 2018]; 15(1):21-30. Disponível em:

https://journal.sobep.org.br/article/brinq uedo-terapeutico-na-assistencia-acrianca-percepcao-de-enfermeiros-dasunidades-pediatricas-de-um-hospitaluniversitario/

16. Oliveira JD, Miranda MLF, Monteiro MFV, Almeida VCF. O brincar e a criança hospitalizada: visão de enfermeiras. Rev Baiana Enferm. [Internet]. 2016 [citado em 20 jun 2018]; 30(4):1-8 Disponível em:

https://portalseer.ufba.br/index.php/enfer magem/article/view/16414/pdf 17. Gomes MFP, Silva ID, Capellini VK. Conhecimento dos profissionais de enfermagem sobre a utilização do brinquedo no cuidado as crianças hospitalizadas. Rev Enferm UFPI. [Internet]. 2016 [citado em 20 jun 2018]; 5(1):23-27. Disponível em: https://revistas.ufpi.br/index.php/reufpi/a rticle/view/4490/pdf 18. Fujita JALM, Carmona EV, Shimo AKK, Macena EH. Uso da metodologia da problematização com o Arco de Maguerez no ensino sobre brinquedo terapêutico. Rev Port Educ. [Internet]. 2016 [citado em 14 set 2018];

29(1):229-58. Disponível em: https://dx.doi.org/10.21814/rpe.5966

RECEBIDO: 27/08/2019

APROVADO: $20 / 10 / 2020$

PUBLICADO: 04/2021 